\section{Antibacterial properties of quercetin}

\author{
Renu Narendra Jaisinghani \\ Department of Microbiology, Smt \\ Chandibai Himmathmal Mansukhani \\ College, Mumbai, India
}

\begin{abstract}
Quercetin is a polyphenolic flavonoid with potential chemoprotective properties. In the present work its antibacterial properties were studied against Staphylococcus aureus, Escherichia coli, Shigella flexneri, Proteus vulgaris, Pseudomonas aeruginosa, Lactobacillus casei var shirota by broth dilution method. Quercetin inhibited S. aureus, $P$. aeruginosa at concentration 20 $\mathrm{mcg} / \mathrm{mL}$ while $P$. vulgaris and $E$. coli were inhibited at concentration $300 \mathrm{mcg} / \mathrm{mL}$ and $400 \mathrm{mcg} / \mathrm{mL}$ respectively. Shigella flexneri and Lactobacillus casei var shirota were completely indifferent even at concentration of $500 \mathrm{mcg} / \mathrm{mL}$.
\end{abstract}

\section{Introduction}

Quercetin is a polyphenolic bioflavonoid found in fruits and vegetables. It belongs to flavonol group of flavonoids. It is known to have antioxidant, antiartherogenic, anti-inflammatory, ${ }^{1}$ anti-carcinogenic, ${ }^{2}$ neuroprotection properties, ${ }^{3}$ antibacterial, ${ }^{4,5}$ and antiviral properties. ${ }^{6}$ Quercetin also has GRAS (Generally Recognized As Safe) status. ${ }^{7}$

The spoilage and poisoning of foods by micro-organisms is a problem that has not yet been brought under adequate control despite the range of robust preservation techniques available. ${ }^{4}$ The consumers' acceptance for preservatives with chemical origin is decreasing; therefore the producers are looking for natural compounds which can be an alternative and supplemented to food products which will help to prolong their shelf-life and microbial safety.

In the present study effectiveness of quercetin as antibacterial agent was studied to check its potential to be used as preservative agent or its utilization in functional foods.

\section{Materials and Methods}

Quercetin Dihydrate (Sigma), Sterile Muller and Hinton Broth, Sterile MRS broth, Dimethyl sulphoxide (DMSO) (Hi Media).

\section{Microorganisms}

Staphylococcus aureus NCIM 2079, Escherichia coli NCIM 2065, Pseudomonas aeruginosa NCIM 20136, Proteus vulgaris NCIM 2027, Shigella flexneri NCIM 5265 (Procured from NCL, Pune). Lactobacillus casei var shirota was isolated from Yakult.

\section{Determination of minimum inhibito- ry concentration}

Minimum Inhibitory Concentration (MIC) of the Quercetin was determined using the broth dilution method. ${ }^{8}$ Bacterial strains were first grown on Muller Hinton Medium for 18 to $24 \mathrm{~h}$ at $37^{\circ} \mathrm{C}$. The inoculums of the indicated bacterial strains were transferred into physiological suspension medium and adjusted to 0.5 Mac Farland turbidity standard. Quercetin stock of 10 $\mathrm{mg} / \mathrm{mL}$ was prepared in $10 \%$ DMSO. St. Muller Hinton Broth was used as diluent. Dilutions were prepared in the range of 10 $\mathrm{mcg} / \mathrm{mL}$ to $500 \mathrm{mcg} / \mathrm{mL}$. $0.1 \mathrm{~mL}$ of bacterial inocula was added in each dilution. Growth control and sterility control were maintained. The tubes were incubated at $37^{\circ} \mathrm{C}$ for $24 \mathrm{~h}$. Bacterial growth was indicated by the presence of turbidity. All tests were carried out in triplicates.

The least concentration of Quercetin that did not permit any visible growth of the inoculated test organisms in broth culture was regarded as the minimum inhibitory concentration in each case. ${ }^{9}$

\section{Determination of minimum bacteri- cidal concentration}

After culturing the test organisms separately in Mueller and Hinton broth containing various concentration of the Quercetin, the broth was inoculated onto freshly prepared agar plates to assay for the bactericidal effect. $0.1 \mathrm{~mL}$ from each tube demonstrating no visible growth was removed to spread on sterile nutrient agar plate. The culture was incubated at $37^{\circ} \mathrm{C}$ for $24 \mathrm{~h}$. The lowest concentration of extract which showed no bacterial growth on solid medium after the incubation period was regarded as minimum bactericidal concentration. All samples were assayed in triplicates.

\section{Effect of quercetin on Lactobacillus casei var shirota}

The strain of Lactobacillus casei var shirota was isolated on Sterile MRS agar from commercially available probiotic drink Yakult. Incubated at $30^{\circ} \mathrm{C}$ under anaerobic condition.

The purified culture was preserved on
Correspondence: Renu Narendra Jaisinghani, Smt Chandibai Himmathmal Mansukhani College, Ulhasnagar, Dist: Thane Mumbai 421003, India.

Tel.: +91.9320512121

E-mail: renu.nj24@gmail.com

Key words: Quercetin, Antibacterial, L.casei var shirota.

Acknowledgements: this work was carried out during my tenure at Jai Hind College. I am thankful to the entire Microbiology Department with special thanks to Dr. M.S. Ghayal.

Contributions: the authors contributed equally

Conflict of interest: the authors declare no potential conflict of interest.

Received for publication: 8 September 2016. Accepted for publication: 9 September 2016.

This work is licensed under a Creative Commons Attribution NonCommercial 4.0 License (CC BY-NC 4.0).

(C) Copyright R.N. Jaisinghani, 2017

Licensee PAGEPress, Italy

Microbiology Research 2017; 8:6877

doi:10.4081/mr.2017.6877

sterile MRS agar slants.

The inocula of L.casei var shirota was prepared as described above. Effect of Quercetin on L. casei var shirota was performed in the similar fashion as described for determination of MIC for other bacterial cultures. For confirmation of effect of Quercetin on growth of L. casei var shirota agar well diffusion method was carried out. Culture suspension was prepared in physiological saline. $0.6 \mathrm{ml}$ of culture $\left(\mathrm{OD}_{550}-0.2\right)$ was added to Sterile molten MRS agar and was allowed to set. Wells were punched and each dilution of Quercetin from MIC were put into the wells. The plates were incubated at $30^{\circ} \mathrm{C}$ under anaerobic condition.

\section{Results}

In the present study, a good antibacterial activity of Quercetin was observed. Minimum inhibition concentration of Quercetin against the six studied bacteria ranged between 20-400 $\mathrm{mcg} / \mathrm{mL}$. Staphylococcus aureus and Pseudomonas aeruginosa were inhibited at $20 \mathrm{mcg} / \mathrm{mL}$ while moderate activity was seen against Escherichia coli and Proteus vulgaris and no activity against Shigella flexneri and Lactobacillus casei var shirota which were confirmed by Minimum Bactericidal con- 
Table 1. Minimum inhibitory concentration (MIC) and minimum bactericidal concentration (MBC) of quercetin.

\begin{tabular}{lcc} 
Bacteria & MIC $(\mathrm{mcg} / \mathrm{mL})$ & MBC $(\mathrm{mcg} / \mathrm{mL})$ \\
Staphylococcus aureus NCIM2079 & 20 & 50 \\
Escherichia coli NCIM2065 & 400 & $>500$ \\
\hline Proteus vulgaris NCIM2027 & 300 & $>500$ \\
Shigella flexneri NCIM5265 & NA & - \\
\hline Pseudomonas aeruginosa NCIM2036 & 20 & 50 \\
Lactobacillus casei var shirota & no activity & -
\end{tabular}

centration and agar well diffusion method respectively (Table 1). This results are in agreement with earlier investigations reported by other authors to inhibit different microorganisms such as E. coli, Klebsiella pneumoniae, Bacillus cereus, A. parasiticus, A. flavus, S. aureus, S. epidermidis, $B$. subtilis, $M$. luteus and $E$. coli in concentration ranging from $100-500 \mathrm{mcg} / \mathrm{mL} .{ }^{4}$ Also, in another study with Coumarin and Quercetin, antimicrobial activity of these agents against gastroenteritis bacterial strain is documented. ${ }^{10}$

\section{Discussion}

The antibacterial properties of Quercetin are clear from work of( Rauha JP2000; Nitiema LW2012). Also the present studies shows effectiveness of Quercetin as antibacterial agent on selected organisms. Shigella flexeneri NCIM5265, Lactobacillus casei var shirota is unaffected by Quercetin.

This interaction between Quercetin and Lactobacillus casei var shirota can be utilized for development of functional foods; the same is evaluated further. Environmental factors and the genetic make-up of the host can modulate the distribution of microbial strains, diet appears to be a major factor in regulating the concentration of individual species of microorganisms that colonize the gut. ${ }^{11}$ Recent research has unveiled a potential therapeutic role of indigenous non-pathogenic microorganisms (probiotics) in maintenance of human health and treatment of various gastrointestinal diseases. ${ }^{12}$ In addition, the use of plants for medicinal purposes has been, and remains, common practice throughout much of the world. Plants contain several bioactive compounds, including phytosterols, phytoestrogens, polyphenols and polyunsaturated fatty acids. ${ }^{13}$ Many of these compounds have been investigated for their anti-inflammatory, antioxidant and/or anticarcinogenic properties, and have been shown to modulate numerous immunological and cellular functions. ${ }^{14,15}$ It has been well documented that intake of flavonol rich foods can modify the composition of gut microbiota exerting pre-biotic like effect. ${ }^{16,19}$ Unabsorbed dietary phenolics and their metabolites have been shown to exert antimicrobial or bacteriostatic effect. ${ }^{17,18}$ These metabolites selectively inhibit pathogen growth while favouring growth of commensals bacteria and in few cases its rather found to favour growth of Lactobacillus and Bifidobacterium. ${ }^{16,17}$ It is clear that flavanol and probiotics have beneficial effects.

\section{Conclusions}

In conclusion, the antibacterial properties of Quercetin can be used in preservation of food. Also a carefully designed, mechanistic-based laboratory and clinical studies will help in developing functional foods containing flavonols and pro-biotics.

\section{References}

1. Abbey EL, Rankin JW. Effect of quercetin supplementation on repeatedsprint performance, xanthine oxidase activity, and inflammation. Int J Sport Nutr Exerc Metab 2011;91-6.

2. Fresco P, Borges F, Marques M, Diniz C. The anticancer properties of dietary polyphenols and its relation with apoptosis. Curr Pharm Des 2010;16:114-34.

3. Sasaki N, Toda T, Matsuo M. Protective effects of flavonoids on the cytotoxicity of linoleic acid hydroperoxide toward rat pheochromocytoma PC12 cells. Chem Bio Interact 2003;145:101-16.

4. Rauha JP, Remes S, Heinonen M, et al. Antimicrobial effects of Finnish plant extracts containing flavonoids and other phenolic compounds. Int $\mathrm{J}$ Food Microbiol 2000;56:3-12.

5. Cushnie TP, Lamb AJ. Antimicrobial activity of flavonoids. Int $\mathbf{J}$ Antimicrob Agents 2005;26:343-56.

6. Gatto MT, Falcocchio S, Grippa E, et al. Antimicrobial and anti-lipase activity of Quercetin and its C2-C16 3-O-acyl esters. Bioorg Med Chem 2002;10:26972.

7. U.S. Food and Drug Administration. GRAS Notice 000341: Quercetin. Available from: www.fda.gov/downloads/food/ingredientspackaginglabeling/gras/noticeinventory/ucm269541.p df

8. Wiegand I, Hilpert K, Hancock R. Agar and broth dilution methods to determine the minimum inhibitory concentration (MIC) of antimicrobial substances. Nat Protocols 2008;3:163-75.

9. Collins GH, Lynes PM, Grange JM. Microbiological methods. 7th ed. Oxford: Butterwort Heinemann Ltd.; 1995. pp 175-90.

10. Nitiema LW, Savadogo A, Simpore J et al. In vitro antimicrobial activity of some phenolic compounds (Coumarin and Quercetin) against gastroenteritis bacterial strains. Int $\mathrm{J}$ Microbiol Res 2012;3:183-7.

11. Penner R, Fedorak R, Madsen K. Probiotics and nautracuticals:nonmedicinal treatments of gastrointestinal diseases. Curr Opin Pharmacol 2005;5:596-603.

12. Montrose DC, Floch MH. Probiotics used in human studies. J Clin Gastroenterol 2005;39:469-84.

13. Foster BC, Arnason JT, Briggs CJ. Natural health products and drug disposition. Annu Rev Pharmacol Toxicol 2005;45:203-26.

14. Mechanick JI. The rational use of dietary supplements and nutraceuticals in clinical medicine. Mt Sinai J Med 2005;72:161-5.

15. Barnes S, Prasain J. Current progress in the use of traditional medicines and nutraceuticals. Curr Opin Plant Biol 2005;8:324-8.

16. Tzonuis X, Vulevic J, Kuhnle GG, et al. Flavanol monomer-induced changes to the human faecal microflora. Br J Nutr 2008;99:782-92.

17. Lee HC, Jenner AM, Low CS, Lee YK. Effect of tea phenolics and their aromatic fecal bacterial metabolites on intestinal microbiota. Res Microbiol 2006;157:876-84.

18. Karaaslan M, Ozden M, Vardin H, Turkoglu H. Phenolic fortification of yoghurt using grape and callus extracts, LWT. Food Sci Technol 2011;44:106572.

19. Karou D, Dicko MH, Simpore J, Traore AS. Antioxidant and antibacterial activities of polyphenols from ethnomedicinal plants of Burkina Faso. Afr J Biotechnol 2005;4:823-28. 